Journal of Mathematics and Statistics 8 (1): 114-121, 2012

ISSN 1549-3644

(C) 2012 Science Publications

\title{
Confidence Interval for Cpm Based on Dp,q Distance
}

\author{
Bahram Sadeghpour Gildeh and Samaneh Asghari \\ Department of Statistics, Faculty of Mathematical Science \\ University of Mazandaran, Babolsar, Iran
}

\begin{abstract}
Problem statement: A measurement control system ensures that measuring equipment and measurement processes are fit for their intended use and its importance in achieving product quality objectives. Approach: The manufacturing industries have been making an extensive effort to implement Statistical Process Control (SPC) in their plants and supply bases. Results: Capability indices derived from SPC have received increasing usage not only in capability assessments, but also in the evaluation of purchasing decisions. In most real life applications, real observations of continuous quantities are not precise numbers; in practice, they are more or less imprecise. Since observations of continuous random variables are imprecise the values of related test statistics become imprecise. In some cases Specification Limits (SLs) are not precise numbers and they are expressed in fuzzy terms, so that the classical capability indices could not be applied. Conclusion/Recommendations: In this study we obtain $100(1-\alpha) \%$ fuzzy confidence interval for Cpm fuzzy process capability index, where instead of precise quality we have two membership functions for specification limits.
\end{abstract}

Key words: Fuzzy set, membership function, process capability index, triangular fuzzy number, fuzzy random variable

\section{INTRODUCTION}

Statistical techniques can be helpful throughout the product cycle, including activities prior to manufacturing, in quantifying process variability, in analyzing this variability relative to product requirements or specifications and in assisting development and manufacturing in eliminating or greatly reducing this variability. This general activity is called process capability analysis. Process capability analysis is a very usable statistical technique to demonstrate the process performance. The results of the analysis can be used to improve the process performance. Process capability refers to the uniformity of process. Obviously, the variability in the process is a measure of the uniformity of output.

There may not exist a definition of the "process capability" but in high probability the (real valued) quality characteristic $\mathrm{X}$ of the produced items lies between some lower and upper specification limits LSL and USL (or tolerance interval limits). Therefore the idea of process capability implies that the fraction $p$ of produced nonconforming items should be small if the process is said to be capable.

In the traditional quality management, the most commonly used capability indices like $\mathrm{Cp}, \mathrm{Cpk}$ and $\mathrm{Cpm}$ are used to indicate process capability (for more information see Montgomery, 2008). An underlying assumption is that output process measurements are distributed as normal random variables. Experience shows that the normality assumption is often not met in real world.

Application and observations usually contain fuzziness owing imprecise measurements or described by linguistic variables, For instance, the water level of a river cannot be measured in an exact way because of the fluctuation.

Similarly, temperature in a room is also unable to be measured precisely because of the same reason. Typical example for an imprecise number is the lifetime of a system which cannot, in general, be described by one real number because the time at which the lifetime ends is not a precise number but is more or less imprecise. Other examples of imprecise data are data given by color intensity pictures or readings on analogue measurement equipment. Therefore, the fuzzy sets theory is found to be an appropriate tool in modeling the imprecise data. There have been some attempts to analyze these situations with fuzzy set theory developed by (Zadeh, 1965). In some cases Specification Limits (SLs) are not precise numbers and they are expressed in fuzzy terms, so that the classical capability indices could not be applied. (Parchami et al., 2006) obtained fuzzy confidence interval for fuzzy

Corresponding Author: Bahram Sadeghpour Gildeh, Department of Statistics, Faculty of Mathematical Science University of Mazandaran, Babolsar, Iran 


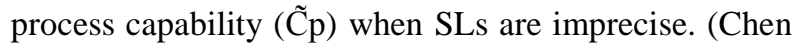
et al., 2008) used the fuzzy analytic method concerning process capability index $\mathrm{Cpm}$ and calculate $\tilde{\mathrm{C} p m}$ for fuzzy observation. (Perakis and Xekalaki, 2004) constructed confidence interval for the index Cpm with crisp data. In this study, we introduce a new fuzzy PCI $(\tilde{\mathrm{C} p m})$ when $S L s$, target and observations are triangular fuzzy number and introduced a $100(1-\alpha) \%$ confidence interval for Cpm fuzzy process capability index, when the engineering specification limits are triangular fuzzy numbers. A set of confidence intervals of sample mean and variance that produces triangular fuzzy numbers for the estimation of $C p k$ index present in (Wu, 2009a). (Wu, 2009b) apply fuzzy sets theory to the statistical confidence interval for unknown fuzzy parameters by considering fuzzy random variables (Hsu and Shu, 2008) present. The fuzzy inference procedure to assess process capability. Generalized confidence intervals for the process capability index $\mathrm{Cpm}$ is proposed as an extension of classical confidence intervals by (Hsu et al., 2008). (Lin and Pearn, 2005) present a testing manufacturing performance based on capability index Cpm. (Parchami and Mashinchi, 2007) assess Fuzzy estimation for process capability indices.

The organization of this study is as follows. We recall some notions of fuzzy number used in this study, which contains the traditional definitions of process capability indices. Then assigned to the presentation of point and interval estimations for Cpm based on fuzzy data. A numerical example is then given at the end.

Preliminariesl: Let $R$ be the set of real numbers and consider sets, $\mathrm{F}(\mathrm{R})=\{\mathrm{A} \mid \mathrm{A}: \mathrm{R} \rightarrow[0,1], \mathrm{A}$ is a continous function $\}, F_{T}(R)=\left\{T_{a, b, c} \mid a, b, c \in R, a \leq b \leq c\right\}$, where Eq. 1:

$\mathrm{T}_{\mathrm{a}, \mathrm{b}, \mathrm{c}}(\mathrm{x})=\left\{\begin{array}{cc}(\mathrm{x}-\mathrm{a}) /(\mathrm{b}-\mathrm{a}) & \text { if } \mathrm{a} \leq \mathrm{x} \leq \mathrm{b} \\ (\mathrm{c}-\mathrm{x}) /(\mathrm{c}-\mathrm{b}) & \text { if } \mathrm{b} \leq \mathrm{x} \leq \mathrm{c} \\ 0 & \text { elsewhere }\end{array}\right.$

Any $\mathrm{A} \in \mathrm{F}(\mathrm{R})$ is called a fuzzy set on $R$ and any $\mathrm{T}_{\mathrm{a}, \mathrm{b}, \mathrm{c}} \in \mathrm{F}_{\mathrm{T}}(\mathrm{R})$ is called a triangular fuzzy number, which we sometimes write as $\mathrm{T}(\mathrm{a}, \mathrm{b}, \mathrm{c})$.

Definition 2.1: Let $T(a, b, c) \in F_{T}(R), k \in R, k \geq 0$. Define the operation $\otimes$ on $\mathrm{F}_{\mathrm{T}}(\mathrm{R})$ as follows Eq. 2:

$\mathrm{k} \otimes \mathrm{T}(\mathrm{a}, \mathrm{b}, \mathrm{c})=\mathrm{T}(\mathrm{a}, \mathrm{b}, \mathrm{c}) \otimes \mathrm{k}=\mathrm{T}(\mathrm{ka}, \mathrm{kb}, \mathrm{kc})$

This operation is called the multipilication of $\mathrm{T}$ ( $\mathrm{a}$, b, c) by k. For $\alpha \in[0,1]$, the $\alpha$-cut of $\mathrm{T}(\mathrm{a}, \mathrm{b}, \mathrm{c})$ is defined by:

$$
(\mathrm{T}(\mathrm{a}, \mathrm{b}, \mathrm{c}))_{\alpha}=\left\{\mathrm{x} \in \mathrm{R} \mid \mathrm{T}_{\mathrm{a}, \mathrm{b}, \mathrm{c}}(\mathrm{x}) \geq \alpha\right\}
$$

Definition 2.2: The Dp,q-distance, indexed by parameter $1<\mathrm{P} \infty, 0 \leq \mathrm{Q}<1$ between two fuzzy numbers $\tilde{A}$ and $\tilde{B}$ is a nonnegative function on $F(R) \times F(R)$ give as follows:

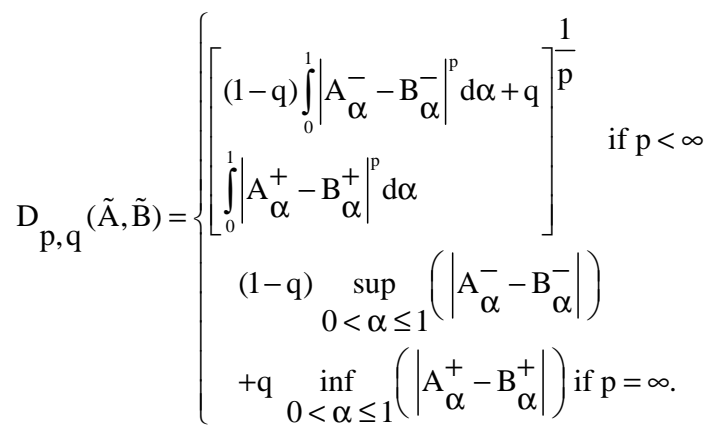

The analytical properties of Dp,q depend on the first parameter $\mathrm{p}$, while the second parameter $\mathrm{q}$ of $\mathrm{Dp}, \mathrm{q}$ characterizes the subjective weight attributed to the sides of the fuzzy numbers. If there are no reasons to distinguish any side of fuzzy numbers, $D_{p, 1 / 2}$ is recommended (For more information see Gildeh and Samaneh, 2001).

Definition 2.3: A mapping $\tilde{\mathrm{X}}: \Omega \rightarrow \mathrm{F}(\mathrm{R})$ is said to be a fuzzy random variable associated with $(\Omega, \mathrm{A})$ if and only if:

$$
(\omega, \mathrm{x}): \mathrm{x} \in \mathrm{X}_{\alpha}(\omega) \in \mathrm{A} \times \mathrm{B}
$$

where B denote the $\sigma$-field of Borel set in R.

Definition 2.4: The central $\mathrm{D}_{2, \mathrm{Q}}$-mean square dispersion of $\tilde{\mathrm{X}}$ about $\tilde{\mathrm{E}}(\tilde{\mathrm{X}}) \quad\left(\right.$ or $\tilde{\mu}_{\tilde{\mathrm{X}}}$ ) is called $\mathrm{D} \operatorname{var}(\tilde{\mathrm{X}})$ given by the value (if it exists):

$$
\begin{aligned}
& \mathrm{D} \operatorname{var}(\tilde{\mathrm{X}})=\mathrm{E}\left(\left[\mathrm{D}_{2, \mathrm{q}}\left(\tilde{\mathrm{X}}, \tilde{\mu}_{\tilde{\mathrm{X}}}\right)\right]^{2}\right)
\end{aligned}
$$

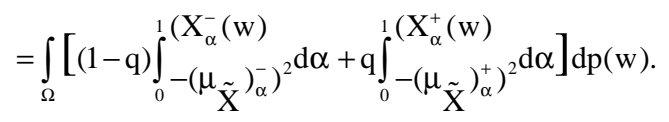

Assume that $\tilde{\mathrm{A}}$ and $\tilde{\mathrm{B}}$ are triangular fuzzy numbers: $\tilde{\mathrm{A}}=\mathrm{T}\left(\mathrm{a}_{1}, \mathrm{a}_{2}, \mathrm{a}_{3}\right)$ and $\tilde{\mathrm{B}}=\mathrm{T}\left(\mathrm{b}_{1}, \mathrm{~b}_{2}, \mathrm{~b}_{3}\right)$, the $\alpha$-cuts of $\tilde{\mathrm{A}}$ and $\tilde{\mathrm{B}}$ are as follows:

$$
\begin{aligned}
& \mathrm{A}_{\alpha}=\left[(1-\alpha) \mathrm{a}_{1}+\mathrm{a}_{2} \alpha, \mathrm{a}_{3} \alpha+(1-\alpha) \mathrm{a}_{4}\right], \\
& \mathrm{B}_{\alpha}=\left[(1-\alpha) \mathrm{b}_{1}+\mathrm{b}_{2} \alpha, \mathrm{b}_{3} \alpha+(1-\alpha) \mathrm{b}_{4}\right]
\end{aligned}
$$

It can be established that: 


$$
\begin{aligned}
& {\left[D_{2,1 / 2}(\tilde{A}, \tilde{B})\right]^{2}=\frac{1}{6}\left[\left(b_{1}-a_{1}\right)^{2}+2\right.} \\
& \left(b_{2}-a_{2}\right)^{2}+\left(b_{3}-a_{3}\right)^{2}+\left(b_{1}-a_{1}\right)\left(b_{2}-a_{2}\right) \\
& \left.+\left(b_{3}-a_{3}\right)\left(b_{2}-a_{2}\right)\right]
\end{aligned}
$$

Proposition 1: Suppose that $\tilde{X}$ be a fuzzy random variable and $\tilde{T} \in F(R)$. Then Eq. 3:

$$
\begin{aligned}
\mathrm{E}\left[\mathrm{D}_{2, \mathrm{q}}(\tilde{X}, \tilde{\mathrm{T}})\right]^{2}=\mathrm{E}\left[\mathrm{D}_{2, \mathrm{q}}\left(\tilde{\mathrm{X}}, \tilde{\mu}_{\tilde{\mathrm{X}}}\right)\right]^{2}+\left[\mathrm{D}_{2, \mathrm{q}}\left(\tilde{\mu}_{\tilde{\mathrm{X}}}, \tilde{\mathrm{T}}\right)\right]^{2} \\
=\mathrm{D} \operatorname{var}(\tilde{X})+\left[\mathrm{D}_{2, \mathrm{q}}\left(\tilde{\mu}_{\tilde{\mathrm{X}}}, \tilde{\mathrm{T}}\right)\right]^{2}
\end{aligned}
$$

\section{Proof:}

$$
\begin{gathered}
\mathrm{E}\left[\mathrm{D}_{2, \mathrm{q}}(\tilde{\mathrm{X}}, \tilde{\mathrm{T}})\right]^{2}=\mathrm{E}\left[(1-\mathrm{q}) \int_{0}^{1} \mathrm{~d} \alpha+\mathrm{q} \int_{0}^{1}\left(\mathrm{X}_{\alpha}^{+}(\mathrm{w})-\mathrm{T}_{\alpha}^{+}\right)^{2} \mathrm{~d} \alpha\right] \\
=(1-\mathrm{q}) \int_{0}^{1} \mathrm{E}\left[\left(\mathrm{X}_{\alpha}^{-}(\mathrm{w})-\mathrm{T}_{\alpha}^{-}\right)\right]^{-} \mathrm{d} \alpha+\mathrm{q} \int_{0}^{1} \mathrm{E}\left[\left(\mathrm{X}_{\alpha}^{+}(\mathrm{w})-\mathrm{T}_{\alpha}^{+}\right)\right] \\
=(1-\mathrm{q}) \int_{0}^{1}\left[\operatorname{var}\left(\mathrm{X}_{\alpha}^{-}\right)+\left(\left(\mu_{\tilde{\mathrm{X}}}\right)_{\alpha}^{-}-\mathrm{T}_{\alpha}^{-}\right)\right]^{2} \\
+\mathrm{q} \int_{0}^{1}\left[\operatorname{var}\left(\mathrm{X}_{\alpha}^{-}\right)+\left(\left(\mu_{\tilde{\mathrm{X}}}\right)_{\alpha}^{-}-\mathrm{T}_{\alpha}^{-}\right)\right]^{2} \\
=\mathrm{D} \operatorname{var}(\tilde{\mathrm{X}})+\left[\mathrm{D}_{2, \mathrm{q}}\left(\tilde{\mu}_{\tilde{\mathrm{X}}}, \tilde{\mathrm{T}}\right)\right]^{2}
\end{gathered}
$$

Similarly, it can be established that Eq. 4:

$$
\begin{aligned}
& \frac{1}{\mathrm{n}} \sum_{\mathrm{i}=1}^{\mathrm{n}}\left[\mathrm{D}_{2, \mathrm{q}}\left(\tilde{\mathrm{X}}_{\mathrm{i}}, \tilde{\mathrm{T}}\right)\right]^{2} \\
& =\frac{1}{\mathrm{n}} \sum_{\mathrm{i}=1}^{\mathrm{n}}\left[\mathrm{D}_{2, \mathrm{q}}(\tilde{\mathrm{X}}, \tilde{\overline{\mathrm{X}}})\right]^{2}+\left[\mathrm{D}_{2, \mathrm{q}}(\tilde{\overline{\mathrm{X}}}, \tilde{\mathrm{T}})\right]
\end{aligned}
$$

where $\hat{D} \operatorname{var}(\tilde{X})$ is estimator of $D \operatorname{var}(\tilde{X})$. That is Eq. 5:

$$
\hat{\mathrm{D}} \operatorname{var}(\tilde{\mathrm{X}})=\frac{1}{\mathrm{n}} \sum_{\mathrm{i}=1}^{\mathrm{n}}\left[\mathrm{D}_{2, \mathrm{q}}(\tilde{\mathrm{X}}, \tilde{\overline{\mathrm{X}}})\right]^{2}
$$

Traditional process capability indices: Process Capability Indices (PCIs) are becoming powerful standard tools for quality report, particularly, at the management level around the world. They measure the ability of a manufacturing process to produce items that meet certain specifications. Numerous Process Capability Indices (PCIs) have been proposed to the manufacturing industry to provide numerical measures of process performance (Kane, 1986; Wu et al., 2009). One of the proposed definitions on process capability index considers that as the ratio of the real performance of process to requested performance that is:

$$
\mathrm{C}_{\mathrm{p}}=\frac{\mathrm{USL}-\mathrm{LSL}}{6 \sigma}
$$

$\mathrm{C}_{\mathrm{p}}$ indicates how well the process fits between upper and lower specification limits and focuses the dispersion of the studied process and does not take into account the centering of the process. The index $\mathrm{C}_{\mathrm{pk}}$ measures the consistency of process quality characteristic relative to the manufacturing tolerance and, therefore, only reflects process potential (or process precision). If the process average is not centered near the midpoint of specifications limits, the $\mathrm{C}_{\mathrm{p}}$ index gives misleading results.

In order to reflect departures from the target value $\left(\mathrm{M}=\frac{\mathrm{USL}+\mathrm{LSL}}{2}\right)$ as well as changes in the process variation several order indices have been proposed such as $\mathrm{C}_{\mathrm{pk}}$ and $\mathrm{C}_{\mathrm{pm}}$ given as Eq. 6 and 7:

$$
\mathrm{C}_{\mathrm{pk}}=\mathrm{C}_{\mathrm{p}}(1-\mathrm{k}), \mathrm{k}=\frac{|\mu-\mathrm{M}|}{\frac{\mathrm{USL}-\mathrm{LSL}}{2}}
$$

And:

$$
C_{\mathrm{pm}}=\frac{\mathrm{USL}-\mathrm{LSL}}{6 \sqrt{\sigma^{2}+(\mu-M)^{2}}}
$$

where, $\mu$ is the distribution center of characteristic X. M is not always equal to $\tau$ which is target value.

$\mathrm{C}_{\mathrm{pk}}$ measures the distance between the process mean and the closest specification limit relation to the one-side actual process spread $3 \sigma . \mathrm{C}_{\mathrm{pk}}$ describes how well the process fits within the specification limits, taking into account the location of the process mean. The index $\mathrm{C}_{\mathrm{pk}}$ takes into account the magnitudes of process variation as well as the degree of process centering, which measures manufacturing performance based on yield (proportion of conformities). Hence, the capability index $\mathrm{C}_{\mathrm{pk}}$ is a yield-based index.

Departures from the target value carry more weight with the other well-known capability index $\mathrm{C}_{\mathrm{pm}}$. The loss-based process capability index $\mathrm{C}_{\mathrm{pm}}$, sometimes called the Taguchi index, has been proposed to the manufacturing industry to measure process performance. In fact, the capability index $\mathrm{C}_{\mathrm{pm}}$ is not primarily designed to provide an exact measure on the number of conforming items, i.e., the process yield. But $\mathrm{C}_{\mathrm{pm}}$ considers the process departure $(\mu-\mathrm{T})^{2}$ (rather than $6 \sigma$ alone) in the denominator of the definition to reflect 
the degrees of process targeting (Chan et al., 1988). The index $\mathrm{C}_{\mathrm{pm}}$ emphasizes measuring the ability of the process to cluster around the target, which therefore reflects the degrees of process targeting (centering). The index $\mathrm{C}_{\mathrm{pm}}$ incorporates with the variation of production items with respect to the target value and the specification limits preset in the factory (Kotz and Lovelace, 1998). In principal, $\mathrm{C}_{\mathrm{pm}}$ behaved like $\mathrm{C}_{\mathrm{pk}}$ but $\mathrm{C}_{\mathrm{pm}}$ is bounded above as $\sigma \rightarrow 0$ and $\mu \neq \mathrm{M}$. For $\mu=\mathrm{M}$ it holds $\mathrm{C}_{\mathrm{p}}=\mathrm{C}_{\mathrm{pk}}=\mathrm{C}_{\mathrm{pm}}$.

Fuzzy proccess capability indices: If we define the specification limits by fuzzy quantities, it is more appropriate to define the process capability indices as fuzzy numbers.

Definition 4.1: Let $\mathrm{L}=\mathrm{T}\left(\mathrm{l}_{1}, \mathrm{l}_{2}, \mathrm{l}_{3}\right), \mathrm{U}=\mathrm{T}\left(\mathrm{u}_{1}, \mathrm{u}_{2}, \mathrm{u}_{3}\right)$ are lower and upper specification limits, where $u_{1} \geq l_{3}$. $\mathrm{T}=\mathrm{T}\left(\mathrm{t}_{1}, \mathrm{t}_{2}, \mathrm{t}_{3}\right)$ is a fuzzy target and observations are triangular fuzzy number too. Then $\tilde{\mathrm{C}}_{\mathrm{pm}}$ is defined as follow (see [14]) Eq. 8:

$\tilde{\mathrm{C}}_{\mathrm{pm}}=\mathrm{k} \otimes \mathrm{T}\left(\mathrm{u}_{1}-\mathrm{l}_{3}, \mathrm{u}_{2}-\mathrm{l}_{2}, \mathrm{u}_{3}-\mathrm{l}_{1}\right)$

Where $\mathrm{k}=\left(6 \sqrt{\mathrm{E}\left(\mathrm{D}_{2,1 / 2}(\tilde{\mathrm{X}}, \tilde{\mathrm{T}})\right)^{2}}\right)^{-1}$

The point estimate for $\tilde{\mathrm{C}}_{\mathrm{pm}}$ is as follows Eq. 9:

$\hat{\tilde{\mathrm{C}}}_{\mathrm{pm}}=\hat{\mathrm{k}} \otimes \mathrm{T}\left(\mathrm{u}_{1}-\mathrm{l}_{3}, \mathrm{u}_{2}-\mathrm{l}_{2}, \mathrm{u}_{3}-\mathrm{l}_{1}\right)$,

Where $\mathrm{k}=\left(6 \sqrt{\frac{1}{\mathrm{n}} \sum_{\mathrm{i}=1}^{\mathrm{n}}\left(\mathrm{D}_{2,1 / 2}\left(\tilde{\mathrm{X}}_{\mathrm{i}}, \tilde{\mathrm{T}}\right)\right)^{2}}\right)^{-1}$

Ranking function: In this study we are going to give a fuzzy confidence interval, where comparing fuzzy numbers is emergent and so an ordering approach is needed. We need a criterion for comparison of two fuzzy subsets. A simple but efficient approach for the ordering of the elements of $F(R)$ is to define a ranking function $\mathrm{R}: \mathrm{F}(\mathrm{R}) \rightarrow \mathrm{R}$ which maps each fuzzy number into the real line, where a natural order exists, (Maleki, 2002). Define the order $\leq \underset{R}{\leq}$ on $F(R)$ by:

$$
\begin{aligned}
& \tilde{\mathrm{A}} \underset{\mathrm{R}}{ } \geq \tilde{\mathrm{B}} \text { if and only if } R(\tilde{\mathrm{A}}) \geq R(\tilde{\mathrm{B}}) \\
& \tilde{\mathrm{A}} \underset{\mathrm{R}}{\leq} \tilde{\mathrm{B}} \text { if and only if } \mathrm{R}(\tilde{\mathrm{A}}) \leq \mathrm{R}(\tilde{\mathrm{B}})
\end{aligned}
$$

$$
\tilde{\mathrm{A}}_{\overline{\mathrm{R}}} \tilde{\mathrm{B}} \text { if and only if } \mathrm{R}(\tilde{\mathrm{A}})=\mathrm{R}(\tilde{\mathrm{B}})
$$

where $\tilde{\mathrm{A}}$ and $\tilde{\mathrm{B}}$ are in $\mathrm{F}(\mathrm{R})$.

Several ranking functions have been proposed by researchers to suit their requirements of the problems under consideration. For more details see (Bortolan and Degani, 1985; Wang and Kerre 2001). The ranking function proposed by Roubens (Fortemps and Roubens, 1996) is defined by Eq. 10:

$\mathrm{R}_{\mathrm{r}}(\tilde{\mathrm{A}})=\frac{1}{2} \int_{0}^{1}\left(\inf \tilde{\mathrm{A}}_{\alpha}+\sup \tilde{\mathrm{A}}_{\alpha}\right) \mathrm{d} \alpha$

From now on, if $R_{r}$ is the Roubens's ranking function, then we write $\underset{\mathrm{R}}{\leq}$ simply as $\leq$. We can easily prove the following lemmas.

Lemma 1: If $\mathrm{T}(\mathrm{a}, \mathrm{b}, \mathrm{c}) \in \mathrm{F}_{\mathrm{T}}$ (R) then Roubens's ranking function reduces to following Eq. 11:

$\mathrm{R}_{\mathrm{r}}(\mathrm{T}(\mathrm{a}, \mathrm{b}, \mathrm{c}))=\frac{2 \mathrm{~b}+\mathrm{a}+\mathrm{c}}{4}$

Lemma 2: Let $m, n \in R, T(a, b, c) \in F_{T}(R)$ and $2 b+a$ $+c \geq 0$. Then according to Roubens's ranking function $\mathrm{m} \otimes \mathrm{T}(\mathrm{a}, \mathrm{b}, \mathrm{c}) \leq \mathrm{n} \otimes \mathrm{T}(\mathrm{a}, \mathrm{b}, \mathrm{c})$ if and only if $\mathrm{m} \leq \mathrm{n}$.

Fuzzy confidence interval for $\tilde{\mathrm{C}}_{\mathrm{pm}}$

Definition 6.1: Let $A, B \in F_{T}(R)$ and $A \leq B$. The fuzzy interval $[A, B]$ is the $\operatorname{set}[A, B]=\left\{C \in F_{T}(R) \mid A \leq C \leq B\right\}$. Note that $[\mathrm{A}, \mathrm{B}]$ is nonempty, since $\mathrm{A}, \mathrm{B} \in[\mathrm{A}, \mathrm{B}]$. Suppose that the set of all random samples of size $n$ which are possible is $\mathrm{X}^{(\mathrm{n})}$.

Definition 6.2: Any function $A: X^{(n)} \rightarrow F_{T}(R)$ is called a fuzzy statistic. Note that $\mathrm{A}\left(\mathrm{X}_{1}, \ldots, \mathrm{X}_{\mathrm{n}}\right)$ only depends on $A\left(X_{1}, \ldots, X_{n}\right)$ and without any unknown parameters. When the observation $X\left(X_{1}, \ldots, X_{n}\right)$ is given, then the value of the statistic, $A(X)$ is just a triangular fuzzy number. Let $\mathrm{X}$ be a measurable random variable on the probability space $(\Omega, F, P)$ and $T=(a, b, c) \in F_{T}(R)$ such that $2 b+a+c \geq 0$. We define Eq. 12:

$(\mathrm{X} \otimes \mathrm{T})(\omega)=\mathrm{X}(\omega) \otimes \mathrm{T}, \quad \forall \omega \in \Omega$

\section{According to definition 2.1:}

Proposition 2: Let $\mathrm{X}$ be a measurable random variable on the probability space $(\Omega, F, P), k_{1}, k_{2} \in \mathrm{R}$ and $\mathrm{T}=\mathrm{T}$ $(\mathrm{a}, \mathrm{b}, \mathrm{c}) \in \mathrm{F}_{\mathrm{T}}(\mathrm{R})$ with $2 \mathrm{~b}+\mathrm{a}+\mathrm{c} \geq 0$. Then: 
$\mathrm{P}\left(\mathrm{k}_{1} \otimes \mathrm{T} \leq \mathrm{X} \otimes \mathrm{T} \leq \mathrm{k}_{2} \otimes \mathrm{T}\right)=1-\alpha$

If and only if $\mathrm{P}\left(\mathrm{k}_{1} \leq \mathrm{X} \leq \mathrm{k}_{2}\right)=1-\alpha$.

Definition 6.3: Let A and B be the observed fuzzy statistic as triangular fuzzy numbers, where $\mathrm{A} \leq \mathrm{B}$. Then $[\mathrm{A}, \mathrm{B}]$ is a $100(1-\alpha) \%$ fuzzy confidence interval for $\mathrm{X} \otimes \mathrm{T}$, where $\mathrm{P}(\mathrm{A} \leq \mathrm{X} \leq \mathrm{B})=1-\alpha$.

Theorem 1: Suppose that $\tilde{X}_{1}, \tilde{X}_{2}, \ldots, \tilde{X}_{n}$ are independent, identically distributed fuzzy random variables with $\mathrm{N}$ $\left(\mu, \sigma^{2}\right)$ and $\mathrm{L}=\mathrm{T}\left(\mathrm{l}_{1}, \mathrm{l}_{2}, \mathrm{l}_{3}\right) \in \mathrm{F}_{\mathrm{T}}(\mathrm{R}), \mathrm{U}=\left(\mathrm{u}_{1}, \mathrm{u}_{2}, \mathrm{u}_{3}\right) \in$ $\mathrm{F}_{\mathrm{T}}(\mathrm{R})$, are lower and upper specification limits (engineering fuzzy limits), where $u_{1} \geq 1_{3}$. Target value is triangular fuzzy number also such as $\mathrm{T}=\mathrm{T}\left(\mathrm{t}_{1}, \mathrm{t}_{2}, \mathrm{t}_{3}\right)$ $\in \mathrm{F}_{\mathrm{T}}(\mathrm{R})$. Then the following interval is a $100(1-\alpha) \%$ fuzzy confidence interval for $\tilde{\mathrm{C}}_{\mathrm{pm}}$ Eq. 13-18:

$$
\left(\hat{\tilde{\mathrm{C}}}_{\mathrm{pm}} \otimes \sqrt{\frac{\chi_{\mathrm{n}, \alpha / 2}^{\prime 2}(\mathrm{n} \delta)}{\mathrm{n}(1+\hat{\delta})}}, \hat{\tilde{\mathrm{C}}}_{\mathrm{pm}} \otimes \sqrt{\frac{\chi_{\mathrm{n}, 1-\alpha / 2}^{\prime 2}(\mathrm{n} \delta)}{\mathrm{n}(1+\hat{\delta})}}\right)
$$

where $\quad \hat{\tilde{\mathrm{C}}}_{\mathrm{pm}}$ is defined with Eq. 2 . $\delta=\frac{\left[\mathrm{D}_{2,1 / 2}(\tilde{\mu}, \tilde{\mathrm{T}})\right]^{2}}{\mathrm{Dvar}}$ and $\chi_{\mathrm{n}, \alpha / 2}^{\prime 2}(\mathrm{n} \delta)$ depicted as the noncentral chi-square with $n$ degrees of freedom and noncentrality parameter $n \delta$.

Proof: The statistic $\sum_{\mathrm{i}=1}^{\mathrm{n}} \frac{\left[\mathrm{D}_{2,1 / 2}\left(\tilde{\mathrm{X}}_{\mathrm{i}}, \tilde{\mathrm{T}}\right)\right]^{2}}{\mathrm{D} \text { var }}$ is distributed as the non- central chi-square with $\mathrm{n}$ degrees of freedom and non-centrality parameter $n \delta$ where $\delta=\frac{\left[\mathrm{D}_{2,1 / 2}(\tilde{\mu}, \tilde{\mathrm{T}})\right]^{2}}{\mathrm{D} \text { var }}($ Vakhania, 1981). We have:

$$
P\left(\begin{array}{l}
\chi_{\mathrm{n}, \alpha / 2}^{\prime 2}(\mathrm{n} \delta)< \\
\frac{\sum_{\mathrm{i}=1}^{\mathrm{n}}\left[\mathrm{D}_{2,1 / 2}\left(\tilde{\mathrm{X}}_{\mathrm{i}}, \tilde{\mathrm{T}}\right)\right]^{2}}{\mathrm{D} \operatorname{var}(\tilde{\mathrm{X}})}<\chi_{\mathrm{n}, 1-\alpha / 2}^{\prime 2}(\mathrm{n} \delta)
\end{array}\right)=1-\alpha
$$

Therefore:

$$
\begin{aligned}
& \mathrm{P}\left(\frac{\chi_{\mathrm{n}, \alpha / 2}^{\prime 2}(\mathrm{n} \delta) \mathrm{D} \operatorname{var}(\tilde{\mathrm{X}})}{\sum\left[\mathrm{D}_{2,1 / 2}\left(\tilde{\mathrm{X}}_{\mathrm{i}}, \tilde{\mathrm{T}}\right)\right]^{2} \mathrm{E}\left[\mathrm{D}_{2,1 / 2}(\tilde{\mathrm{X}}, \tilde{\mathrm{T}})\right]^{2}}<\right. \\
& \frac{1}{\mathrm{E}\left[\mathrm{D}_{2,1 / 2}(\tilde{\mathrm{X}}, \tilde{\mathrm{T}})\right]^{2}}< \\
& \left.\frac{\chi_{\mathrm{n}, 1-\alpha / 2}^{\prime 2}(\mathrm{n} \delta) \mathrm{D} \operatorname{var}(\tilde{\mathrm{X}})}{\sum\left[\mathrm{D}_{2,1 / 2}(\tilde{\mathrm{X}}, \tilde{\mathrm{T}})\right]^{2} \mathrm{E}\left[\mathrm{D}_{2,1 / 2}(\tilde{\mathrm{X}}, \tilde{\mathrm{T}})\right]^{2}}\right)=1-\alpha .
\end{aligned}
$$

By Proposition 1, we can write:

$$
\begin{aligned}
& \mathrm{P}\left(\sqrt{\frac{\chi_{\mathrm{n}, \alpha / 2}^{\prime 2}(\mathrm{n} \delta) \hat{\mathrm{D}} \operatorname{var}(\tilde{\mathrm{X}})}{\mathrm{n} \hat{\mathrm{D}} \operatorname{var}(\tilde{\mathrm{X}})+\mathrm{n}\left[\mathrm{D}_{2,1 / 2}(\tilde{\mathrm{X}}, \tilde{\mathrm{T}})\right]^{2}}}\right. \\
& \times \frac{1}{6 \sqrt{1 / \mathrm{n} \sum\left[\mathrm{D}_{2,1 / 2}(\tilde{\mathrm{X}}, \tilde{\mathrm{T}})\right]^{2}}}<\frac{1}{6 \sqrt{\mathrm{E}\left[\mathrm{D}_{2,1 / 2}(\tilde{\mathrm{X}}, \tilde{\mathrm{T}})\right]^{2}}} \\
& <\sqrt{\frac{\chi_{\mathrm{n}, 1-\alpha / 2}^{\prime 2}(\mathrm{n} \delta) \hat{\mathrm{D}} \operatorname{var}(\tilde{\mathrm{X}})}{\mathrm{n} \hat{\mathrm{D}} \operatorname{var}(\tilde{\mathrm{X}})+\mathrm{n}\left[\mathrm{D}_{2,1 / 2}(\tilde{\overline{\mathrm{X}}}, \tilde{\mathrm{T}})\right]^{2}} \times} \\
& \left.\frac{1}{6 \sqrt{1 / \mathrm{n} \sum\left[\mathrm{D}_{2,1 / 2}(\tilde{\mathrm{X}}, \tilde{\mathrm{T}})\right]^{2}}}\right)=1-\alpha
\end{aligned}
$$

Let:

$$
\begin{aligned}
& \mathrm{k}_{1}=\sqrt{\frac{\chi_{\mathrm{n}, \alpha / 2}^{\prime 2}(\mathrm{n} \delta) \hat{\mathrm{D}} \operatorname{var}(\tilde{\mathrm{X}})}{\mathrm{n} \hat{\mathrm{D}} \operatorname{var}(\tilde{\mathrm{X}})+\mathrm{n}\left[\mathrm{D}_{2,1 / 2}(\tilde{\mathrm{X}}, \tilde{\mathrm{T}})\right]^{2}}} \times \\
& \frac{1}{6 \sqrt{1 / \mathrm{n} \sum\left[\mathrm{D}_{2,1 / 2}(\tilde{\mathrm{X}}, \tilde{\mathrm{T}})\right]^{2}}}
\end{aligned}
$$

And:

$$
\begin{aligned}
& \mathrm{k}_{2}=\sqrt{\frac{\chi_{\mathrm{n}, 1-\alpha / 2}^{\prime 2}(\mathrm{n} \delta) \hat{\mathrm{D}} \operatorname{var}(\tilde{\mathrm{X}})}{\mathrm{n} \hat{\mathrm{D}} \operatorname{var}(\tilde{\mathrm{X}})+\mathrm{n}\left[\mathrm{D}_{2,1 / 2}(\tilde{\overline{\mathrm{X}}}, \tilde{\mathrm{T}})\right]^{2}}} \times \\
& \frac{1}{6 \sqrt{1 / \mathrm{n} \sum\left[\mathrm{D}_{2,1 / 2}(\tilde{\mathrm{X}}, \tilde{\mathrm{T}})\right]^{2}}}
\end{aligned}
$$

By Proposition 2 and the fact $\mathrm{u}_{1} \geq 1_{3}$, we can obtain

$$
\begin{aligned}
& \mathrm{p}\left(\mathrm{k}_{1} \otimes \mathrm{T}\left(\mathrm{u}_{1}-\mathrm{l}_{3}, \mathrm{u}_{2}-\mathrm{l}_{2}, \mathrm{u}_{3}-\mathrm{l}_{1}\right)<\right. \\
& \frac{1}{6 \sqrt{\mathrm{E}\left[\mathrm{D}_{2,1 / 2}(\tilde{\mathrm{X}}, \tilde{\mathrm{T}})\right]^{2}}} \otimes \mathrm{T}\left(\mathrm{u}_{1}-\mathrm{l}_{3}, \mathrm{u}_{2}-\mathrm{l}_{2}, \mathrm{u}_{3}-\mathrm{l}_{1}\right) \\
& \left.<\mathrm{k}_{2} \otimes \mathrm{T}\left(\mathrm{u}_{1}-\mathrm{l}_{3}, \mathrm{u}_{2}-\mathrm{l}_{2}, \mathrm{u}_{3}-\mathrm{l}_{1}\right)\right)=1-\alpha
\end{aligned}
$$

\section{By Definition 2.1:}

$\mathrm{P}\left(\mathrm{T}\left(\mathrm{k}_{1}\left(\mathrm{u}_{1}-\mathrm{l}_{3}\right), \mathrm{k}_{1}\left(\mathrm{u}_{2}-\mathrm{l}_{2}\right), \mathrm{k}_{1}\left(\mathrm{u}_{3}-\mathrm{l}_{1}\right)\right)<\right.$
$\frac{1}{6 \sqrt{\mathrm{E}\left[\mathrm{D}_{2,1 / 2}(\tilde{\mathrm{X}}, \tilde{\mathrm{T}})\right]^{2}}} \otimes \mathrm{T}\left(\mathrm{u}_{1}-\mathrm{l}_{3}, \mathrm{u}_{2}-\mathrm{l}_{2}, \mathrm{u}_{3}-\mathrm{l}_{1}\right)$
$<\mathrm{T}\left(\mathrm{k}_{2}\left(\mathrm{u}_{1}-\mathrm{l}_{3}\right), \mathrm{k}_{2}\left(\mathrm{u}_{2}-\mathrm{l}_{2}\right), \mathrm{k}_{2}\left(\mathrm{u}_{3}-\mathrm{l}_{1}\right)\right)=1-\alpha$

By Eq. 2 of we obtain:

$$
\mathrm{P}\left(\begin{array}{l}
\sqrt{\frac{\chi_{\mathrm{n}, \alpha / 2}^{\prime 2}(\mathrm{n} \delta)}{\mathrm{n}(1+\hat{\delta})}} \otimes \hat{\tilde{\mathrm{C}}}_{\mathrm{pm}}<\tilde{\mathrm{C}}_{\mathrm{pm}} \\
<\sqrt{\frac{\chi_{\mathrm{n}, 1-\alpha / 2}^{\prime 2}(\mathrm{n} \delta)}{\mathrm{n}(1+\hat{\delta})}} \otimes \hat{\tilde{\mathrm{C}}}_{\mathrm{pm}}
\end{array}\right)=1-\alpha
$$


Table 1: 30 triangular fuzzy observation

\begin{tabular}{|c|c|c|}
\hline$\tilde{X}_{1}=(5.856 .156 .35)$ & $\tilde{X}_{11}=\mathrm{T}(5.866 .046 .25)$ & $\tilde{X}_{21}=(5.55 .815 .99)$ \\
\hline$\tilde{\mathrm{X}}_{2}=\left(\begin{array}{l}5.795 .95 .98) \\
\text { (1) }\end{array}\right.$ & $\tilde{X}_{12}=\left(\begin{array}{llll}6.13 & 6.23 & 6.33\end{array}\right)$ & $\tilde{X}_{22}=\left(\begin{array}{lll}5.65 .92 & 6.05\end{array}\right)$ \\
\hline$\tilde{X}_{3}=\left(\begin{array}{ll}5.71 & 5.83 \\
5.99\end{array}\right)$ & $\tilde{X}_{13}=\left(\begin{array}{lll}5.95 & 6.05 & 6.19\end{array}\right)$ & $\tilde{X}_{23}=\left(\begin{array}{l}5.55 \\
5.75 \\
5.95\end{array}\right)$ \\
\hline$\tilde{X}_{4}=\left(\begin{array}{ll}6.05 & 6.18 \\
6.32\end{array}\right)$ & $\tilde{X}_{14}=\mathrm{T}(5.0665 .55 .70)$ & $\tilde{\mathrm{X}}_{24}=\mathrm{T}(5.846 .036 .50)$ \\
\hline$\tilde{\mathrm{X}}_{5}=\mathrm{T}(5.896 .066 .23)$ & $\tilde{X}_{15}=\mathrm{T}(5.655 .745 .84)$ & $\tilde{\mathrm{X}}_{25}=\mathrm{T}(6.056 .306 .50)$ \\
\hline$\tilde{\mathrm{X}}_{6}=\mathrm{T}(6.016 .106 .25)$ & $\tilde{X}_{16}=\mathrm{T}(5.705 .775 .83)$ & $\tilde{\mathrm{X}}_{26}=\mathrm{T}(6.256 .356 .45)$ \\
\hline$\tilde{X}_{7}=\left(\begin{array}{lll}6.15 & 6.20 & 6.30\end{array}\right)$ & $\tilde{X}_{17}=\mathrm{T}(6.236 .326 .40)$ & $\tilde{\mathrm{X}}_{27}=\mathrm{T}(5.655 .866 .05)$ \\
\hline$\tilde{\mathrm{X}}_{8}=\mathrm{T}(5.645 .816 .05)$ & $\tilde{X}_{18}=\mathrm{T}(5.605 .705 .08)$ & $\tilde{\mathrm{X}}=\mathrm{T}(5.705 .875 .95)$ \\
\hline$\tilde{\mathrm{X}}_{9}=\mathrm{T}(5.85 .95 .98)$ & $\tilde{\mathrm{X}}_{19}=\mathrm{T}(5.855 .956 .05)$ & $\tilde{\mathrm{X}}_{29}=\mathrm{T}(5.755 .955 .15)$ \\
\hline$\tilde{X}_{10}=\mathrm{T}(6.016 .126 .24)$ & $\tilde{X}_{20}=\mathrm{T}(5.906 .006 .10)$ & $\tilde{X}_{30}=\mathrm{T}(6.106 .236 .46)$ \\
\hline
\end{tabular}

Table 2: Fuzzy confidence interval

\begin{tabular}{llll}
\hline $1-\alpha$ & Fuzzy confidence interval \\
\hline 0.8 & $\mathrm{~T}\left(\begin{array}{llll}0.5570 & 0.7161 & 0.8752\end{array}\right) \leq \tilde{\mathrm{C}}_{\mathrm{pm}} \leq \mathrm{T}\left(\begin{array}{lll}0.5950 & 0.7650 & 0.9349\end{array}\right)$ \\
0.85 & $\mathrm{~T}\left(\begin{array}{lllll}0.5617 & 0.7222 & 0.8827\end{array}\right) \leq \tilde{\mathrm{C}}_{\mathrm{pm}} \leq \mathrm{T}\left(\begin{array}{llll}0.5901 & 0.7587 & 0.9273\end{array}\right)$ \\
0.9 & $\mathrm{~T}\left(\begin{array}{lllll}0.5664 & 0.7283 & 0.8901\end{array}\right) \leq \tilde{\mathrm{C}}_{\mathrm{pm}} \leq \mathrm{T}\left(\begin{array}{llll}0.5853 & 0.7525 & 0.9198\end{array}\right)$ \\
0.95 & $\mathrm{~T}\left(\begin{array}{llll}0.5712 & 0.7343 & 0.8975\end{array}\right) \leq \tilde{\mathrm{C}}_{\mathrm{pm}} \leq \mathrm{T}\left(\begin{array}{llll}0.5806 & 0.7464 & 0.9123\end{array}\right)$ \\
\hline
\end{tabular}

Hence:

$$
\left(\sqrt{\frac{\chi_{\mathrm{n}, \alpha / 2}^{\prime 2}(\mathrm{n} \delta)}{\mathrm{n}(1+\hat{\delta})}} \otimes \hat{\tilde{\mathrm{C}}}_{\mathrm{pm}}, \sqrt{\frac{\chi_{\mathrm{n}, 1-\alpha / 2}^{\prime 2}(\mathrm{n} \delta)}{\mathrm{n}(1+\hat{\delta})}} \otimes \hat{\tilde{\mathrm{C}}}_{\mathrm{pm}}\right)
$$

Is a $100(1-\alpha) \%$ fuzzy confidence interval for $\tilde{\mathrm{C}}_{\mathrm{pm}}$. Note that any $\tilde{\mathrm{C}}_{\mathrm{pm}}=\mathrm{T}(\mathrm{a}, \mathrm{b}, \mathrm{c})$, with:

$$
\mathrm{R}_{\mathrm{r}}\left(\tilde{\mathrm{C}}_{\mathrm{pm}}\right) \in\left(\begin{array}{l}
\mathrm{R}_{\mathrm{r}}\left(\sqrt{\frac{\left.\chi_{\mathrm{n}, \alpha / 2}^{\prime 2} \mathrm{n} \delta\right)}{\mathrm{n}(1+\hat{\delta})}} \otimes \hat{\tilde{\mathrm{C}}}_{\mathrm{pm}}\right), \\
\mathrm{R}_{\mathrm{r}}\left(\sqrt{\frac{\left.\chi_{\mathrm{n}, 1-\alpha / 2}^{\prime 2} \mathrm{n} \delta\right)}{\mathrm{n}(1+\hat{\delta})}} \otimes \hat{\tilde{\mathrm{C}}}_{\mathrm{pm}}\right)
\end{array}\right)
$$

Is in the $100(1-\alpha) \%$ fuzzy confidence interval given in Theorem 1 if the following inequalities hold:

$$
\frac{\mathrm{u}_{1}-\mathrm{l}_{3}}{6 \sqrt{\frac{1}{\mathrm{n}} \sum_{\mathrm{i}=1}^{\mathrm{n}}\left[\mathrm{D}_{2,1 / 2}\left(\tilde{\mathrm{X}}_{\mathrm{i}}, \tilde{\mathrm{T}}\right)\right]}} \sqrt{\frac{\chi_{\mathrm{n}, \alpha / 2}^{\prime 2}(\mathrm{n} \delta)}{\mathrm{n}(1+\hat{\delta})}} \leq \mathrm{a}
$$

$$
\mathrm{c} \leq \frac{\mathrm{u}_{3}-\mathrm{l}_{1}}{6 \sqrt{\frac{1}{\mathrm{n}} \sum_{\mathrm{i}=1}^{\mathrm{n}}\left[\mathrm{D}_{2,1 / 2}\left(\tilde{X}_{\mathrm{i}}, \tilde{\mathrm{T}}\right)\right]}} \sqrt{\frac{\chi_{\mathrm{n}, 1-\alpha / 2}^{\prime 2}(\mathrm{n} \delta)}{\mathrm{n}(1+\hat{\delta})}}
$$

And:

$$
\begin{aligned}
& \frac{\mathrm{u}_{2}-1_{2}}{\sqrt[6]{\frac{1}{\mathrm{n}_{\mathrm{i}=1}^{\mathrm{n}} \sum_{1}\left[\mathrm{D}_{2,1 / 2}\left(\tilde{X}_{\mathrm{i}}, \tilde{T}\right)\right]}} \sqrt{\frac{\chi_{\mathrm{n}, \alpha / 2}^{\prime 2}(\mathrm{n} \delta)}{\mathrm{n}(1+\hat{\delta})}}<\mathrm{b}} \\
& <\frac{\mathrm{u}_{2}-1_{2}}{\sqrt[6]{\frac{1}{\mathrm{n}_{\mathrm{i}} \sum_{\mathrm{i}=1}^{\mathrm{n}}\left[\mathrm{D}_{2,1 / 2}\left(\tilde{\mathrm{X}}_{\mathrm{i}}, \tilde{\mathrm{T}}\right)\right]}} \sqrt{\frac{\left.\chi_{\mathrm{n}, 1-\alpha / 2}^{\prime 2} \mathrm{n} \delta\right)}{\mathrm{n}(1+\hat{\delta})}}}
\end{aligned}
$$

Or:

$$
\sqrt{\frac{\chi_{n, \alpha / 2}^{\prime 2}(\mathrm{n} \delta)}{\mathrm{n}(1+\hat{\delta})}}<\frac{6 \mathrm{~b} \sqrt{\frac{1}{\mathrm{n}} \sum_{\mathrm{i}=1}^{\mathrm{n}}\left[\mathrm{D}_{2,1 / 2}\left(\tilde{\mathrm{X}}_{\mathrm{i}}, \tilde{\mathrm{T}}\right)\right]}}{\mathrm{u}_{2}-1_{2}}<\sqrt{\frac{\chi_{\mathrm{n}, 1-\alpha / 2}^{\prime 2}(\mathrm{n} \delta)}{\mathrm{n}(1+\hat{\delta})}}
$$

$$
\text { Let } \lambda \in\left(\sqrt{\frac{\chi_{n, \alpha / 2}^{\prime 2}(\mathrm{n} \delta)}{\mathrm{n}(1+\hat{\delta})}}, \sqrt{\frac{\chi_{\mathrm{n}, 1-\alpha / 2}^{2}(\mathrm{n} \delta)}{\mathrm{n}(1+\hat{\delta})}}\right)
$$




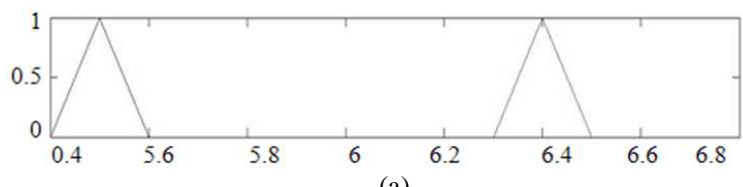

(a)

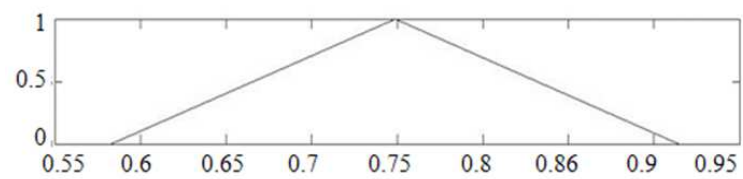

(b)

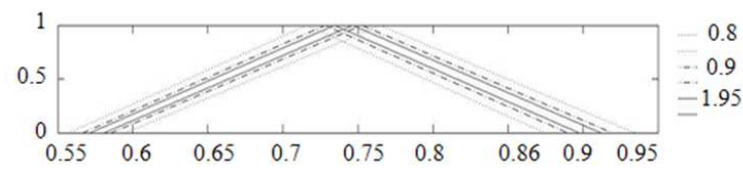

(c)

Fig. 1: Fuzzy process specification

Then any $\tilde{\mathrm{C}}_{\mathrm{pm}}=\lambda \otimes \hat{\tilde{\mathrm{C}}}_{\mathrm{pm}}$ is in the $100(1-\alpha) \%$ fuzzy confidence interval given in Theorem1. The noncentral chi-square distribution can be approximated (Pearson, 1959).

Numerical example: Table 1 shows the Fuzzy data given in (Chen et al., 2008). In this example, LSL = $(5.4,5.5,5.6)$, $\mathrm{USL}=(6.3,6.4,6.5)$ and $\mathrm{T}=\mathrm{T}(5.9,6$, 6.1). Fig 1a shows the membership function of fuzzy process specification limits. The value of $\tilde{\mathrm{C}}_{\mathrm{pm}}$ based on the definition 2.5 is $\mathrm{T}=\mathrm{T}(0.5823,0.7487,0.9151)$ as shown in Fig1b. We present $100(1-\alpha) \%$ confidence intervals using the Theorem 1 in Table 2 and illustrate these fuzzy confidence intervals in Fig. 1c.

\section{REFERENCES}

Bortolan, G. and R. Degani, 1985. A review of some methods for ranking fuzzy subsets. Fuzzy Sets Syst., 15: 1-19. DOI: 10.1016/0165-0114(85)90012-0

Chan, L.K., S.W. Cheng and F.A. Spiring, 1988. A New Measure of Process Capability: Cpm. J. Qual. Tech., 20: 162-173.

Chen, C.C., C.M. Lai and H.Y. Nien, 2008. Measuring process capability index $\mathrm{Cpm}$ with fuzzy data. Qual. Quan., 44: 529-535. DOI: 10.1007/s11135008-9211-x

Fortemps, P. and M. Roubens, 1996. Ranking and defuzzification methods based on area compensation. Fuzzy Sets Syst., 82: 319-330. DOI: 10.1016/0165-0114(95)00273-1
Gildeh, B.S. and A. Samaneh, 2001. A new method for constructing confidence interval for $\mathrm{Cpm}$ based on fuzzy data. Int. J. Quality Res., 5: 67-73.

Hsu, B.M, C.W. Wu and M.H. Shu, 2008. Generalized confidence intervals for the process capability index C pm. Metrika, 68: 65-82. DOI 10.1007/s00184-007-0143-6

Hsu, B.M. and M.H. Shu, 2008. Fuzzy inference to assess manufacturing process capability with imprecise data. Eur. J. Opera. Res., 186: 652-670. DOI:10.1016/j.ejor.2007.02.023

Kane, V.E., 1986. Process capability indices. J. Qual. Tech., 181: 41-52.

Kotz, S. and C.R. Lovelace, 1998. Process Capability Indices in Theory and Practice. 1st Edn., Arnold, New York, London, ISBN-10: 0340691778 pp: 279.

Lin, P.C. and W.L. Pearn, 2005. Testing manufacturing performance based on capability index Cpm. Int. J. Adv. Manuf. Technol., 27: 351-358. DOI: 10.1007/s00170-004-2182-8

Maleki, H.R., 2002. Ranking functions and their applications to fuzzy linear programming. Far East J. Math. Sci., 4: 283-301.

Montgomery, D.C., 2008. Introduction to Statistical Quality Control. 6th Edn., Wiley, Hoboken, ISBN: 9780470169926 pp: 734.

Parchami, A. and M. Mashinchi, 2007. Fuzzy estimation for process capability indices. Inform. Sci., 177 : 1452-1462. DOI: 10.1016/j.ins.2006.08.016

Parchami, A., M. Mashinchi and H.R. Maleki, 2006. Fuzzy confidence interval for fuzzy process capability index. J. Intel. Fuzzy Syst., 17: 287-295.

Pearson, E.S., 1959. Note on an approximation to the distribution of non-central $\chi^{2}$. Biometrika, 46: 364364. DOI: $10.2307 / 2333533$

Perakis, M. and E. Xekalaki, 2004. A new method for constructing confidence intervals for the index $\mathrm{C}_{\mathrm{pm}}$. Qual. Reliab. Eng. Int., 20: 651-665. DOI: 10.1002/qre.574

Vakhania, N.N., 1981. Probability distribution on linear space. Elsevier Science Publishes.

Wang, X. and E.E. Kerre, 2001. Reasonable properties for the ordering of fuzzy quantities (I). Fuzzy Sets Syst., 118: 375-385. DOI: 10.1016/S01650114(99)00062-7

Wu, C.W., 2009a. Decision-making in testing process performance with fuzzy data. Eur. J. Operational Res., 193: 499-509. DOI: 10.1016/j.ejor.2007.11.044 
Wu, C.W., W.L. Pearn and S. Kotz, 2009. An overview of theory and practice on process capability indices for quality assurance. Int. J. Produ. Econ., 117: 338-359. DOI: $10.1016 /$ j.ijpe.2008.11.008

Wu, H.C., 2009b. Statistical confidence intervals for fuzzy data. Exp. Syst. Appli., 36: 2670-2676. DOI: 10.1016/j.eswa.2008.01.022
Zadeh, L.A., 1965. Fuzzy sets. Inform. Control, 8: 338353. DOI: 10.1016/S0019-9958(65)90241-X 